\title{
Iritis and iris atrophy after eyebrow epilation with alexandrite laser
}

This article was published in the following Dove Press journal:

Clinical Ophthalmology

7 December 2011

Number of times this article has been viewed

Zachary Elkin'

Milan P Ranka'

Eleanore T Kim'

Ronit Kahanowicz'

Wayne G Whitmore ${ }^{2}$

'Department of Ophthalmology, New York University; ${ }^{2}$ Department of Ophthalmology, New York

Presbyterian Hospital, Weill Cornell Medical College, New York, NY, USA

Correspondence: Milan P Ranka New York University School of Medicine, Department of Ophthalmology, 462 First Avenue, NBV 5N 18, New York, NY I0016, USA

Tel +l 2122633263

Fax + I 2 I 22638749

Email milan.ranka@nyumc.org
Purpose: To report a case of bilateral iritis and transillumination defects after laser hair removal of the eyebrows with an alexandrite laser.

Methods: A 41-year-old male presented with bilateral eye pain and mild photophobia 2 days after receiving alexandrite $(755 \mathrm{~nm})$ laser epilation of both eyebrows. Examination showed visual acuity of 20/20 in both eyes, $2+$ conjunctival injection in both eyes, $1+$ cells in the anterior chamber of right eye and trace cells in left eye, poor right pupil dilation, and left pupil without movement. Intraocular pressure and fundus examination were normal. He was diagnosed with iritis and iris atrophy, associated with laser epilation. Topical steroids and cycloplegic drops were prescribed for 1 month.

Results: After 1 month of treatment, transillumination defects remained in both eyes, but greater in right. In dim light, the right pupil was $4 \mathrm{~mm}$ and oval and the left pupil was $6 \mathrm{~mm}$ and round. Visual acuity remained 20/20 in both eyes.

Conclusion: Laser hair removal of the eyebrows can lead to permanent ocular damage even with eye protection, and should be avoided.

Keywords: laser hair removal, transillumination defects, alexandrite laser

\section{Introduction}

Laser hair epilation remains one of the most popular and effective treatments for longterm removal of unwanted hair. With multiple treatments, hair reduction of $74 \%-84 \%$ can be seen at 18 months. ${ }^{1}$ Epilation lasers include red spectrum ruby (694 nm), near infrared spectrum alexandrite $(755 \mathrm{~nm})$, diode $(800-810 \mathrm{~nm})$, neodymium: yttrium-aluminum garnet (1064 nm), and intense pulse light (590-1200 nm). While nonophthalmologic complications of laser epilation have been extensively described in the literature, there are only a few case reports of ocular complications with laser epilation of the eyebrows. ${ }^{2-7}$

Most case reports occurred with the diode $(810 \mathrm{~nm})$ laser in female patients. The female patients previously described presented between 1 day and 1 week with pain, redness, photophobia, and blurred vision. Examinations were significant for iris atrophy, anterior chamber reactions, posterior synechiae, and abnormal dilation. Herbold et al described a case of bilateral pigment dispersion and anterior subcapular cataracts in a 27-year-old female following epilation with a diode laser. ${ }^{3}$ In previous cases, the observed iritis appeared to improve after 1-5 weeks of topical steroids, but the iris atrophy remained. Carrim et al was the only group to describe a case with the less penetrating alexandrite laser, leading to acute anterior uveitis, pigment dispersion with secondary increased intraocular pressure, and transillumination defects. ${ }^{4}$ 
This report describes a new case of a male patient with iritis and iris atrophy after receiving laser epilation of the eyebrows with an alexandrite $(755 \mathrm{~nm})$ laser while not wearing protective eyewear.

\section{Case report}

A 41-year-old Caucasian male with hypertension and no significant past ocular history, specifically no history of uveitis, presented with bilateral eye pain and mild photophobia 2 days after receiving alexandrite $(755 \mathrm{~nm})$ laser epilation of both eyebrows. While the patient was at an appointment for laser epilation of his back, he asked that the laser be used on his eyebrows as well. He reported that he closed his eyes and covered them with his fingers during the treatment. He did not wear any protective eyewear. Shortly after the treatment, the patient had pain and redness in both eyes, without change in vision.

The patient presented 2 days later with worsening pain, redness, and photophobia. Visual acuity was $20 / 20$ in both eyes. The examination was significant for $2+$ conjunctival injection bilaterally, $1+$ cells in the anterior chamber of the right eye, and trace cells in the left eye. Intraocular pressure was within normal limits. There was corectopia of the right pupil with poor dilation of the temporal side. The left pupil was round without movement. No synechiae were appreciated. Fundus examination was within normal limits. The patient was started on topical steroids for his iritis and cycloplegic drops for the atonic pupils.

One week later, the right eye still had an anterior chamber reaction with an irregular $(4.0 \times 4.5 \mathrm{~mm})$ pupil. The left eye was quiet with a round pupil, dilating to $5.5 \mathrm{~mm}$. At his 2-week follow-up, both eyes were quiet, however multiple transillumination defects were noted in both eyes (Figures 1 and 2). Medications were tapered. At 1 month,

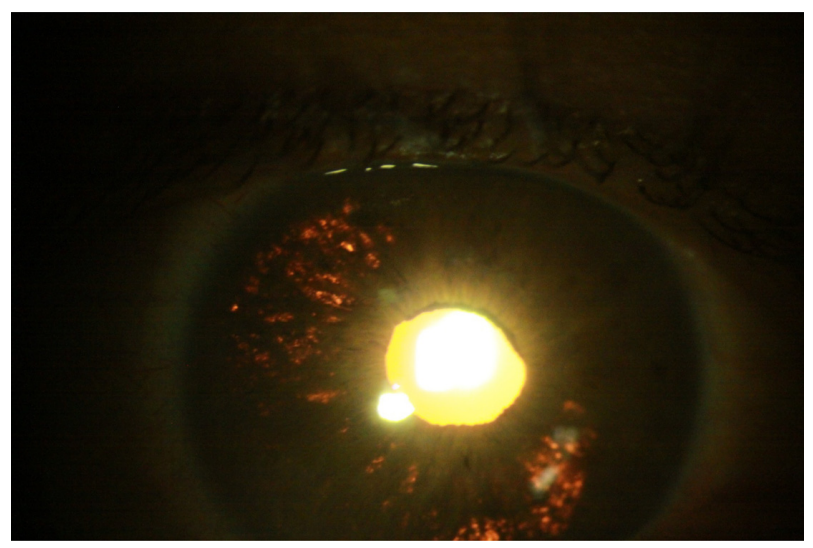

Figure I Transillumination defects of the right eye at 2 weeks.

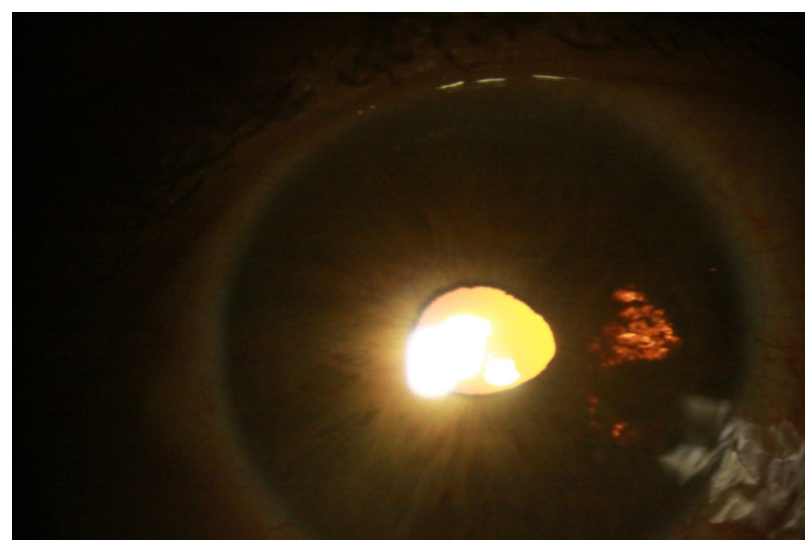

Figure 2 Transillumination defects of the left eye at 2 weeks.

visual acuity remained 20/20 in both eyes. In bright light, both pupils were $3 \mathrm{~mm}$ and round. In dim light, the right pupil was $4 \mathrm{~mm}$ and oval and the left pupil was $6 \mathrm{~mm}$ and round. Ocular tensions and fundus examination remained normal.

\section{Discussion}

Laser epilation uses selective photothermolysis to remove unwanted hair. The red and near infrared wavelengths of the lasers penetrate into the dermis, where they are absorbed by melanin in hair follicles. ${ }^{1}$ The light is pulsed at a fast enough frequency to damage the hair follicles without transmitting energy to the surrounding tissue. Surrounding pigmented tissues, however, compete for the energy leading to the common side effects of pain, erythema, and skin pigment changes. In particular, alexandrite and diode lasers, which differ by wavelength, were designed for deeper penetration of the skin to prevent these side effects in patients with darker skin.

When used on the superficial coarse hair of the eyebrow, these lasers risk penetrating the thin skin of the eyelid and damaging the pigmented structures of the eye. In the clinic where this patient received his laser hair removal, the spot size used for the alexandrite laser is $8-12 \mathrm{~mm}$, which allows for a minimum penetration of $2-3 \mathrm{~mm}$. As described in previous reports, the normal Bell's phenomenon of upgaze with closed eyes will align the pigmented iris with the peripheral beams of the laser. ${ }^{2}$ As evident by the normal fundus examinations, the laser did not appear to penetrate deep enough to damage the pigmented retina.

Notable in most of the cases is the lack of protective eyewear during the laser treatment. Safety goggles, however, were reportedly used in two of the cases. ${ }^{5,6}$ There was no mention of the use of metal shields as eye protection for 
these procedures or whether metal shields would provide better protection. Furthermore, the iris trauma in this case was due to penetrated and not scattered, reflected, or misdirected laser energy. Therefore, protective goggles over the eyes would not have prevented damage since the laser was pointed at hair with the eye directly underneath. This hair and skin had to be exposed for the desired hair removal.

The importance of this case report is to illustrate that ocular damage can occur with the less penetrating alexandrite laser and continues to occur despite published reports. Given these permanent ocular complications, even with protective eyewear, the use of laser hair removal of the eyebrows is dangerous and should not be performed. If this method is to be chosen, physicians, technicians, and patients should be more educated about the specific ocular complications that can occur.

\section{Disclosure}

The authors report no conflicts of interest in this work.

\section{References}

1. Lapidoth M, Dierickx C, Lanigan S, et al. Best practice options for hair removal in patients with unwanted facial hair using combination therapy with laser: guidelines drawn up by an expert working group. Dermatology. 2010;221(1):34-42.

2. Brilakis HS, Holland EJ. Diode-laser-induced cataract and iris atrophy as a complication of eyelid hair removal. Am J Ophthalmol. 2004; 137(4):762-763.

3. Herbold TM, Busse H, Uhlig CE. Bilateral cataract and corectopia after laser eyebrow epilation. Ophthalmology. 2005;112(9):1634-1635.

4. Carrim ZI, Chohan AW, Devlin HC. Iris damage and acute pigment dispersion following photo-epilation. Eye (Lond). 2006;20(12):1486-1488.

5. Sheikh A, Hodge W, Coupland S. Diode laser-induced uveitis and visual field defect. Ophthal Plast Reconstr Surg. 2007;23(4):321-323.

6. Halkiadakis I, Skouriotis S, Stefanaki C, et al. Iris atrophy and posterior synechiae as a complication of eyebrow laser epilation. $J$ Am Acad Dermatol. 2007;57(2 Suppl):S4-S5.

7. Shulman S, Bichler I. Ocular complications of laser-assisted eyebrow epilation. Eye (Lond). 2009;23(4):982-983.
Clinical Ophthalmology

\section{Publish your work in this journal}

Clinical Ophthalmology is an international, peer-reviewed journal covering all subspecialties within ophthalmology. Key topics include: Optometry; Visual science; Pharmacology and drug therapy in eye diseases; Basic Sciences; Primary and Secondary eye care; Patien Safety and Quality of Care Improvements. This journal is indexed on

Submit your manuscript here: http://www.dovepress.com/clinical-ophthalmology-journal

\section{Dovepress}

PubMed Central and CAS, and is the official journal of The Society of Clinical Ophthalmology (SCO). The manuscript management system is completely online and includes a very quick and fair peer-review system, which is all easy to use. Visit http://www.dovepress.com/ testimonials.php to read real quotes from published authors. 